\title{
Digital Signage sebagai Media Penyampaian Informasi Kegiatan Akademik Berbasis Mikrokomputer
}

\author{
I Wayan Aditya Suranata*1, I Nyoman Kusuma Wardana ${ }^{2}$ \\ ${ }^{1,2}$ Sistem Komputer STMIK STIKOM Bali \\ E-mail: ${ }^{* 1}$ aditya.kutri@gmail.com ${ }^{2}$ kusumawardana@ ${ }^{2}$ tikom-bali.ac.id
}

\begin{abstract}
Abstrak
Penelitian ini menerapkan salah satu jenis mikrokomputer, yaitu Raspberry Pi Tipe B yang digunakan sebagai perangkat pemroses inti sebuah sistem pengelola konten berbasis web pada digital signage untuk kepentingan akademik. Sistem pengelola konten yang dibangun pada penelitian ini menggunakan framewok berbasis Drupal 7 dan sistem operasi Raspbian Wheezy. Berdasarkan penelitian sebelumnya, penggunaan digital signage sebagai media untuk menyebarkan informasi memiliki beberapa keunggulan dibandingkan dengan media konvensional, seperti media cetak. Digital signage mampu menampilkan informasi yang lebih atrakif dan dapat menarik pengunjung lebih banyak. Kelebihan yang dimiliki oleh sebuah mikrokomputer, seperti harga yang relatif terjangkau, ukurannya yang kecil (seukuran kartu ATM), dan konsumsi daya yang rendah (3,5 Watt) bisa dipadukan dengan penggunaan digital signage dalam hal pemilihan perangkat pemroses inti. Dari hasil pengamatan yang dilakukan peneliti selama eksperimen, mikrokomputer mampu menjalankan antarmuka berbasis web dinamis yang menampilkan konten multimedia seperti gambar dan efek transisi yang atraktif dengan baik untuk keperluan penyampaian informasi akademik di Laboratorium Robotics and Embedded Systems STMIK STIKOM Bali.
\end{abstract}

Kata Kunci —Academic Information Display, Digital Signage, Raspberry Pi

\begin{abstract}
This study implements a kind of microcomputers which is called Raspberry Pi type B as a core processing device of digital signage for academic purposes. The content management systems constructed in this study used Drupal framewok and Raspbian Wheezy as operating systems. Compared to the conventional method (printed brochures, etc.), the use of microcomputers for displaying information offer some advantages. According to the previous work, it is concluded that digital signage can be more attractively invite the audiences. A relatively affordable price, small size (at the size of an ATM card), and low power consumption (approximately 3.5 Watts), make the microcomputer as an ideal choice for digital signage. According to the obtained results, the microcomputer is capable to run a dynamic web-based interface that displays a multimedia content such as images and transition effects etc. for academic information systems implemented at the Laboratory of Robotics and Embedded Systems STMIK STIKOM Bali.
\end{abstract}

Keywords - Academic Information Display, Digital Signage, Raspberry Pi

\section{PENDAHULUAN}

Digital signage merupakan perangkat pengelola konten digital yang telah diprogram untuk dapat menampilkan urutan informasi atau pesan kepada target penonton secara efektif, cepat, tepat dan handal. Digitalsignage memanjakan mata dalam memberikan tontonan visual yang menarik dan atraktif. Informasi yang ditampilkan dapat memiliki format multimedia 
berupa gambar, video, text bergerak, grafik, tabel, jadwal, berita, ataupun informasi ramalan cuaca. Informasi-informasi ini dapat ditampilkan dengan baik menggunakan media displai elektronik seperti LCD TV, PLASMA TV, Proyektor, dan digital billboard.

Banyak kelebihan yang ditawarkan oleh digitalsignage sebagai media untuk menyebarkan informasi ke target penonton daripada media konvensional. Digital signage bersifat dinamis, kontennya diperbaharui kapanpun sesuai kebutuhan tanpa harus mengeluarkan biaya lagi untuk percetakan. Sistem ini bersifat fleksibel dan kontennya dapat diatur secara terpusat sehingga menguntungkan bila penempatannya tersebar di banyak cabang. Konten sistem ini dapat bersifat dinamis dan atraktif, sertamemiliki kekuatan visual yang lebih untuk menarik perhatian penonton. Penggunanaan media ini pada bidang pemasaran dapat menaikkan citra perusahaan maupun brandeddari produk yang ditawarkan.

Digital signage mempunyai ruang lingkup penerapan yang sangat luas. Segala aspek bisnis atau proses kerja yang memerlukan sebuah media komunikasi visual yang handal dapat menggunakan teknologi ini pada proses kerja padaperkantoran, restoran, bank, pemerintahan, retail (toko \&shoppingmall), pendidikan, kesehatan, transportasi, entertainment dan digitaloutdoor. Perusahaan atau perkantorandapat menggunakan teknologi ini untuk menyampaikan pesan dan informasi penting ke seluruh cabangnya dengan cepat dan realtime. Untuk keperluan bisnisperbankan dan lembaga finansial, sistem ini dapat menampilkan informasi nilai saham, kurs valuta asing, dan suku bunga secara realtime.Pada restoran dan retail, sistem ini dapat menampilkan menu makanan dan informasi produk dengan lebih atraktif dan menarik.

Untuk penerapan dibidang pendidikan seperti kampus,sistem ini dapat digunakan sebagai informasi kegiatan perkuliahan, jadwal kuliah, event, serta sistem yang terintegrasi dengan media sosial seperti Twitter dapat digunakan sebagai pemberitahuan cepat apabila dosen atau staf pengajar berhalangan hadir.Pesan dari dosen dapat langsung ditampilkan pada layar hanya dengan men-tweet ke akun sistem melalui Twitter. Manfaatnya, Mahasiswa dapat menghemat waktu tanpa harus menunggu lama pada suatu kegiatan perkuliahan. Keseluruhan sistem ini secara singkat dapat disebut sebagai Academic Information Display (AID).

Berbagai penelitian mengenai teknologi digital signage telah dilakukan, seperti mengeksplorasi bagaimana merancang digital signage yang berpusat pada pengguna untuk kinerja wayfinding yang lebih baik. Penelitian ini difokuskan pada evaluasi informasi digital signage kampus sebagai alat wayfinding, yang berguna bagi pengunjung kampus. Tulisan ini memeriksa dua evaluasi, evaluasi formatif dan evaluasi sumatif, dalam konteks bagaimana pengguna yang menilai kekayaan dari sistem yang berkaitan dengan desain digital signage sebelum konstruksi, dan pengujian validitas dan menentukan dampak dari desain digital signage. Hasil penelitian menunjukkan bahwa digital signage lebih efisien daripada signage kertas atau signage tradisional. Integrasi metode ini membantu mengidentifikasi konten yang efektif dan fitur desain digital signagewayfinding untuk studi di masa depan [1].

Penelitian mengenai efektifitas dari digital signage juga dilakukan. Pada penelitian tersebut, peneliti menggunakan data mining untuk menyelidiki hasil dari iklan digital di bidang penyiaran melalui sistem digital signage. Dalam studi ini, peneliti bertujuan untuk memahami efektivitas digital signage - apakah iklan yang menarik target pelanggan. Berdasarkan program komersial yang diminta oleh klien, peneliti menggunakan teknologi pengenalan wajah dan data mining untuk mengenali fitur wajah pelanggan dari sudut yang berbeda ketika menghadapi tampilan layar. Selanjutnya, peneliti menentukan apakah konsumen menonton iklan dan mencatat durasi menontonnya. Terakhir, peneliti menganalisis data yang diperoleh untuk mengevaluasi efektivitas iklan digital signage. Percobaan ini menunjukkan bahwa pendekatan peneliti adalah layak dan dapat memenuhi harapan pengguna [2].

Untuk menekan biaya, telah diteliti metode yang membangun model distribusi untuk konten lokal, menautkan konten lokal ke digital signage, dan mendistribusikannya. Penelitian tersebut menggunakan pendekatan "satu-sumber, multi-guna", secara otomatis mengambil konten lokal ke database, mendaftarkan pada database digital signage, kemudian menampilkannya. Peneliti telah mendesain dan mengembangkan purwarupa berdasarkan 
penelitian tersebut, dan menerapkannya uji coba lapangan pada digital signage untuksarana transportasi trem [3].

Dari berbagai keuntungan yang ditawarkan teknologi digital signage, tentunya ada kendala yang masih harus dihadapi. Digital signage memerlukan sebuah komputer pengolah konten multimedia, yang artinya, biaya yang harus dikeluarkan untuk perancangan, pengadaan alat, pemeliharaan, hingga konsumsi daya listrik yang diperlukan cukup tinggi. Dari masalah tersebut beragam solusi juga tersedia, salah satunya adalah mengganti perangkat pemroses inti digital signage dengan sebuah mikrokomputer.

Mikrokomputer dapat digunakan sebagai mesin pengolah konten multimedia pada digital signage. Keuntungannya yaitu biaya untuk pengadaan sebuah mikrokomputer relatif terjangkau, ukurannya yang kecil (sebesar kartu ATM), dan tentunya konsumsi dayanya yang hemat dibandingkan dengan komputer personal (desktop) membuatnya layak untuk mensubtitusi penggunaan komputer sebagai inti pemroses sebuah digital signage. Jenis mikrokomputer yang beredar dipasaran saat ini sangat beragam, seperti yang berarsitektur ARM Raspberry Pi Tipe B (Raspi B). Raspi B mampu menjalankan sistem pengelola konten berbasis web, yang pada penelitian ini menggunakan Drupal 7. Kombinasi antara sistem operasi berbasis Linux Debian dan sistem pengelola konten berbasis web dengan Drupal 7 yang berjalan pada mikrokomputer Raspi B memberikan berbagai kemampuan yang mumpuni untuk penerapan teknologi digital signage. Selanjutnya, pada penelitian ini, penggunaaan mikrokomputer akan difokuskan sebagai Academic Information Display (AID) pada Laboratorium Robotics and Embedded Systems STMIK STIKOM Bali.

\section{METODE PENELITIAN}

\subsection{Mikrokomputer}

Mikrokomputer yang digunakan pada penelitian ini adalah Raspberry PI tipe B (Raspi B). Raspi B mempunyai arsitektur berbasis ARMv6, dengan RAM sebersar 512MB dan Prosesor dengan clockspeed $700 \mathrm{MHz}$. Untuk sistem operasi, sistem ini menggunakan distro Linux berbasis Debian yang di kastem build untuk arsitektur ARM dengan nama Raspbian, dan versi build-nya sendiri adalah Raspbian Wheezy. Daya yang dibutuhkan tidak begitu besar, yaitu sebesar 5 Volt tegangan searah (DC) dan konsumsi arus sebesar $700 \mathrm{~mA}$. Raspi B sendiri telah dilengkapi berbagai antarmuka yang terdiri dari 8 General Purpose Input Output (GPIO) pin, USB 2.0 Port x 2, RJ-45 x 1, Audio jack 3.5 x 1, HDMI x 1, 1 slot Micro SD, dan konektor kamera dan LCD masing-masing berjumlah 1 buah. Bentuk dan ukuran Raspi B diperlihatkan pada Gambar 1.

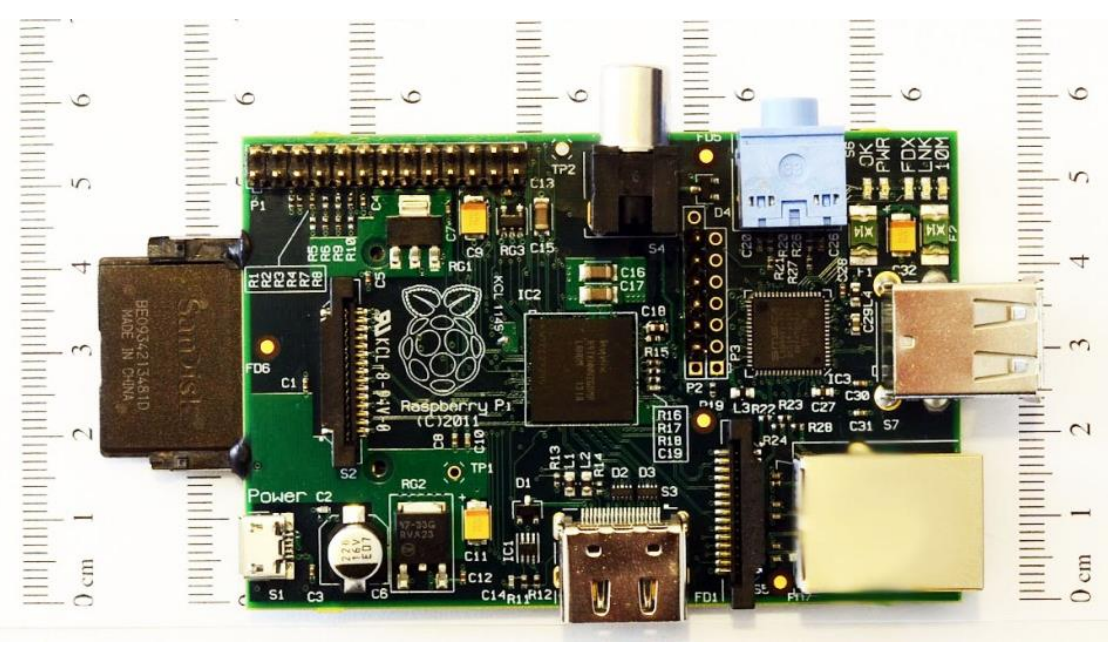

Gambar 1. Raspberry PI Tipe B 


\subsection{Sistem Pengelola Konten}

Sistem pengelola konten digunakan untuk mengatur dan mengontrol material konten yang berskala besar dan dinamis. Sistem pengelola konten memfasilitasi pembuatan konten, kontrol konten, proses edit, proses filter, dan banyak fungsi pengaturan konten lainnya. Pada umumnya, terdapat dua cara untuk mengelola konten yang ditampilkan pada digital signage, yaitu pengelola konten berbasis desktop dan berbasis web.

Platform berbasis web memiliki beragam keunggulan dibandingkan dengan platform berbasis desktop. Platform berbasis web lebih fleksibel dari segi implementasi dan pengembangan. Dengan menggunakan platform berbasis web, sistem pengelola konten tidak terlalu terpengaruh oleh lingkungan sistem penunjangnya.

Pada sistem berbasis desktop, sedikit perubahan pada lingkungan seperti sistem operasi yang digunakan akan menyebabkan masalah. Berbeda dengan sistem pengelola konten berbasis web, perubahan yang terjadi pada level sistem operasi sekalipun tidak akan mempengaruhi bagaimana sistem bekerja, selama sistem operasi tersebut mendukung lingkungan kerja untuk aplikasi berbasis web maka sistem pengelola konten masih dapat berjalan.

Dari berbagai sistem pengelola konten berbasis web yang populer dan banyak orang gunakan seperti Wordpress dan Joomla, salah satu yang memungkinkan dan mendukung untuk penggunakan pada digital signage adalah Drupal. Drupal sendiri merupakan sebuah teknologi sistem pengelola konten yang tersusun dari beberapa lapisan dan lingkungan pendukung seperti komputer server, sistem operasi, database, web server, PHP, dan Drupal sendiri, seperti yang diperlihatkan pada Gambar 2.

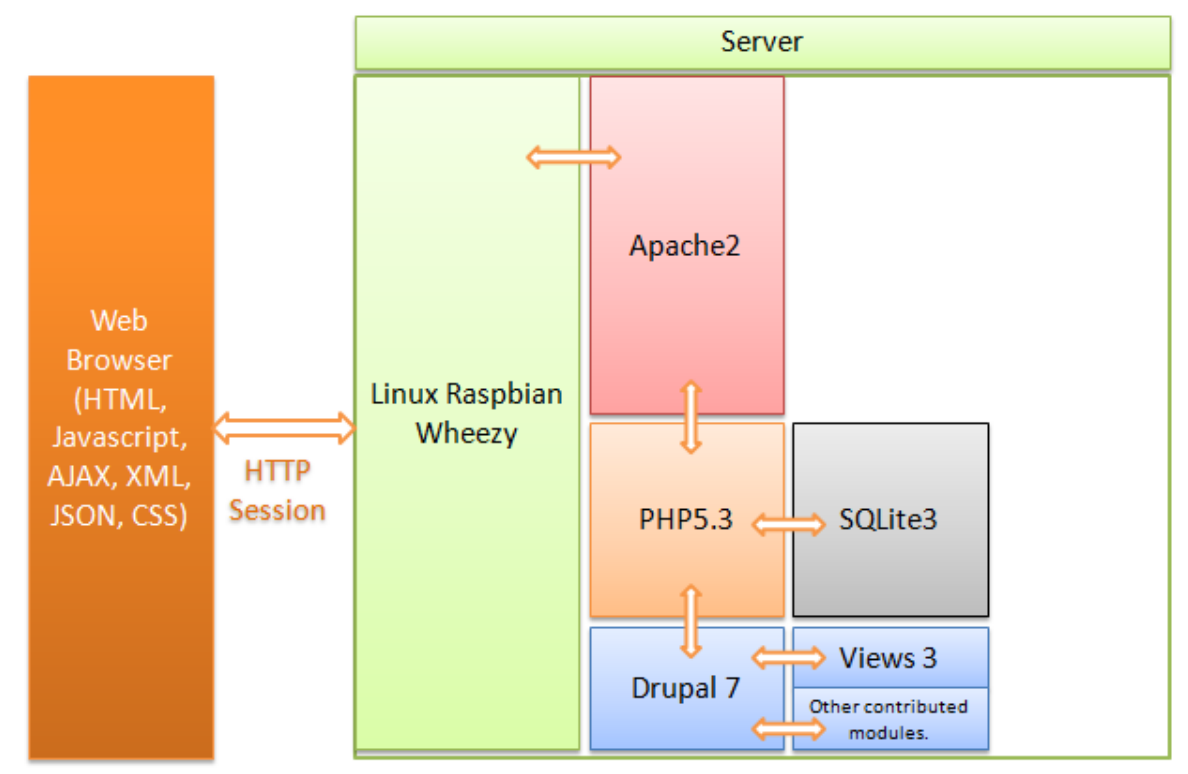

Gambar 2. Susunan sistem pengelola konten berbasis web

\subsection{Contributed Modules}

Sistem Drupal bisa mendapatkan banyak kemampuan ketika dipasangkan dengan modul kontribusi dari komunitas. Selain Drupal 7 sendiri, Views merupakan download terpopuler kedua untuk Drupal. Faktanya, Views sangat populer dan sekarang telah dimasukan sebagai modul inti pada Drupal 8. Konsep kerja dari modul Views sendiri mirip seperti querybuilder sekaligus contentformatter. Dari Views, dimungkinkan untuk memilih konten atau field, memfilter, hingga memformat bagaimana bentuk informasi yang akan ditampilkan. Semua terintegrasi pada Views UI, bahkan query dari hasil pembuatan Views tersebut dapat diamati secara langsung. Informasi query dari Vies diperlihatkan pada Gambar 3. 


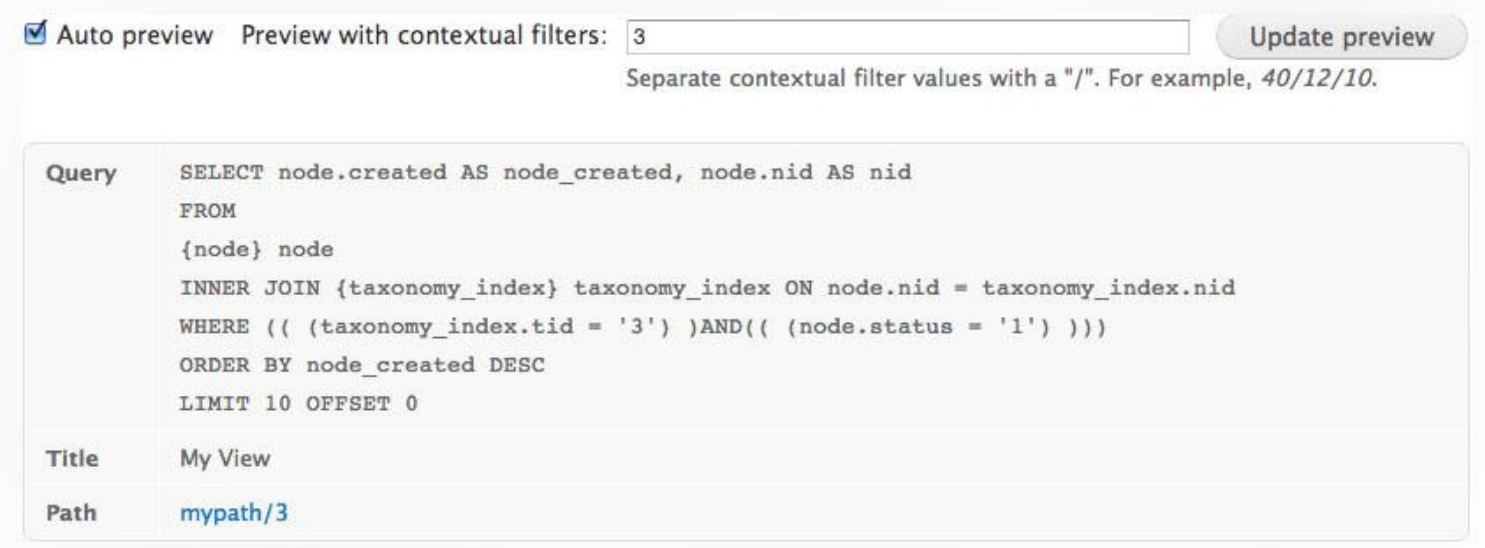

Gambar 3. Informasi query dari Views

Pada Views UI, dari berbagai menu yang ada, pada dasarnya dapat dibagi menjadi dua kerangka kerja. Pertama, pemilihan konten dan field dari tipe konten yang telah dibuat dipilih untuk ditampilkan pada output berupa block atau page. Block merupakan kotak yang terlihat di berbagai area pada halaman website Drupal. Bagaimana susunan dan cara kerja block yang dimaksud akan muncul pada halaman bergantung pada dua hal, antara pengaturan pada tema yang aktif dan administrative block settings.

Kedua, mengatur bagaimana memformat konten yang akan ditampilkan dan cara menampilkannya. Views memungkinkan konten untuk diformat menjadi beragam bentuk tampilan, secara bawaan terdapat pilihan untuk menampilkan konten dalam bentuk Grid, HTML list, Jump menu, Table dan Unformatted list. Karena dukungan yang besar dari komunitas, kini setidaknya terdapat 300 lebih modul kontribusi yang terintegrasi dengan modul Views [4]. Dengan demikian, selain membuat tampilan kastem untuk konten dari awal, kini modul lain yang terintegrasi dengan Views dapat dimanfaatkan untuk membuat tampilan konten yang lebih menarik dan atraktif seperti Views Slideshow, dengan modul ini dimungkinkan untuk membuat tampilan slideshow dinamis menggunakan jQuery dengan beragam pilihan animasi.

Selain Views, modul umum yang digunakan dalam mengelola dan memasukan konten pada Drupal adalah Content Construction Kit (CCK) yang pada versi 7 telah diangkat menjadi coremodule. Dengan CCK dimungkinkan untuk membuat field kastem untuk tipe node yang telah dibuat. Untuk fungsi file unggah, modul Multiupload Filefield Widget biasa digunakan untuk mengunggah file secara berbanyak, dan versi khususnya Multiupload Imagefield Widget digunakan untuk mengupload file gambar secara berbanyak.

Antarmuka digitalsignage yang dinamis juga menjadi masalah yang perlu dipecahkan, sistem antarmuka web memerlukan pengambilan data secara realtime tanpa harus me-reload halaman secara keseluruhan. Karena bila hal tersebut terjadi, bukan hanya membebani server namun juga akan menghilangkan kesan canggih yang dimiliki oleh signage digital. Dari permasalahan tersebut ada solusi yang ditawarkan oleh teknologi web yaitu AJAX. 
Citec Journal, Vol. 1, No. 4, Agustus 2014 - Oktober 2014

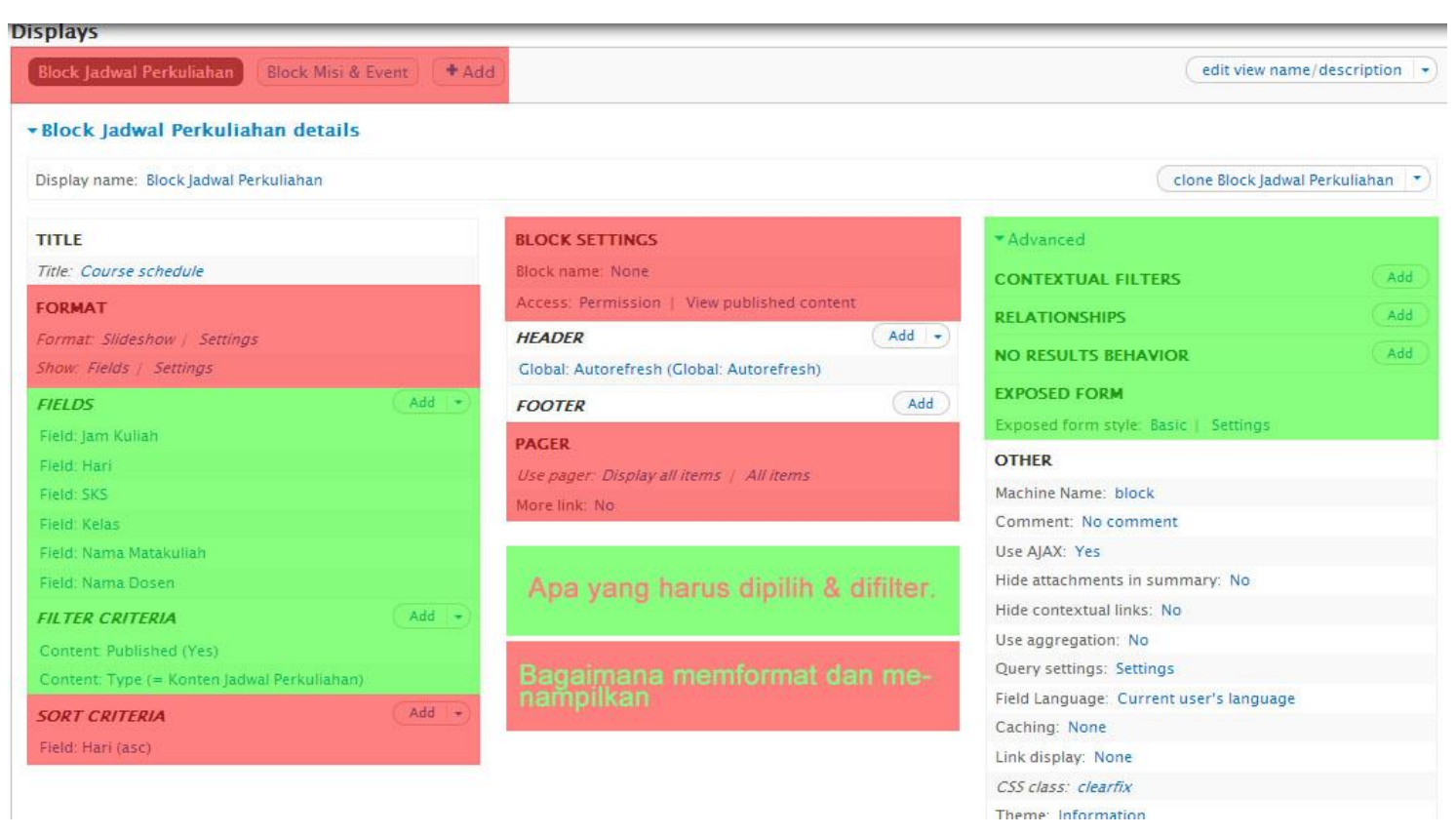

Gambar 4. Views User Interface

Ajax (juga AJAX; singkatan dari Asynchronous JavaScript and XML) [5] adalah sekelompok teknik pengembangan web saling terkait yang digunakan pada sisi klien untuk membuat aplikasi web asinkron. Dengan Ajax, aplikasi web dapat mengirim data ke, dan mengambil data dari, server secara asinkron (di latar belakang) tanpa mengganggu layar dan perilaku dari halaman yang ada. Data dapat diambil dengan menggunakan object XMLHttpRequest. Meskipun namanya berisi XML, penggunaan XML tidak diperlukan (JSON sering digunakan sebagai gantinya.), dan permintaannya tidak perlu asinkron [6].

Drupal 7 sendiri telah menggunakan teknologi AJAX pada antarmukanya. Untuk block juga dimungkinkan untuk melakukan refresh/reload konten secara asinkron dengan menggunakan modul Block Refresh dan Views Auto-Refresh. Dengan menggunakan Block Refresh dan Views Auto-Refresh, block-block yang diseting menggunakan fungsi ini bisa disetel agar meng-update kontenya setiap sekian interval waktu yang ditentukan secara otomatis tanpa harus me-reload halaman secara keseluruhan.

\subsection{Lingkungan Pendukung untuk Mode Kiosk}

Lingkungan kiosk merupakan lingkungan yang menunjang web browser untuk membuka halaman web yang berisi informasi signage yang akan ditampilkan secara khusus. Dengan mengatur lingkungan desktop menjadi mode kiosk, hal-hal yang tidak perlu seperti taskbar dan sistem tray bisa dihilangkan untuk menghemat sumber daya. Ketika mikrokumputer booting-up dan masuk ke mode kiosk, hanya komponen desktop yang diperlukan oleh web browser yang akan dimuat.

Untuk membuat lingkungan kiosk, dibutuhkan windowmanager kastem dan web browser yang memang didesain untuk tujuan tersebut. Salah satunya adalah Matchbox window manager dan Chromium. Kursor dan scrollbar pada mode kiosk dinon-aktifkan karena tidak berfungsi dan untuk memperindah tampilan dari digital signage.

\subsection{Integrasi Dengan Situs Luar dan Media Sosial}

Selain menampilkan konten secara internal, digital signage dapat dintegrasikan dengan situs luar yang terhubung dengan internet. Situs berita, informasi cuaca, dan perbankan biasa digunakan sebagai sumber untuk informasi yang akan ditampilkan pada signage digital. Beragam metode untuk melakukan pengambilan konten tersedia, namun umumnya yang 
digunakan adalah metode parsing dari halaman feed atau RSS yang disediakan khusus oleh masing-masing website untuk tujuan sharing data.

Format dari feed atau RSS yang dipublikasikan oleh website umumnya memiliki format XML atau JSON. Hal ini sangat menguntungkan karena format tersebut bisa dengan mudah diekstrak dan diambil datanya menggunakan fungsi built-in yang dimiliki oleh PHP. Json_decode, salah satu fungsi untuk men-decode sebuah halaman web berformat JSON untuk diterjemahkan menjadi sebuah variabel array. Selanjutnya variabel array yang telah terbentuk bisa dengan mudah diekstrak dengan melakukan perulangan foreach.

Media sosial seperti Twitter juga telah menerapkan Application Programming Interface (API) yang berformat JSON. Hal ini tentu bisa dimanfaatkan untuk membuat digital signage menjadi interaktif. Dengan adanya API Twitter ini, dimungkinkan untuk melakukan interaksi dengan akun Twitter yang khusus diintegrasikan dengan digital signage. Seperti membaca mention yang ditujukan ke akun signage digital, pesan yang dikirimkan selanjutnya bisa diolah. Jika pesan dikirim dengan format tertentu, seperti menggunakan hastag kata-kata khusus, maka bisa dilakukan pemanggilan fungsi khusus melalui PHP. Sebagai contoh, untuk sebuah mention bisa ditampilkan pada sebuah block, mention bisa diformat dengan menyertakan hastag\#infodosen. Selanjutnya, fungsi strpos yang dimiliki oleh PHP bisa digunakan untuk melakukan templatematching untuk menentukan apakah mention yang masuk tersebut akan ditampilkan pada block.

Melakukan pemanggilan API Twitter menggunakan PHP diperlukan pustaka OAuth. OAuth adalah standar terbuka untuk otorisasi. OAuth menyediakan metode untuk klien agar dapat mengakses sumber daya server atas nama pemilik sumber daya seperti klien yang berbeda atau pengguna akhir. Tersedia banyak pustaka untuk bisa terhubung ke Twitter, dari yang multiplatform (iOS, Android, Java, PHP, Python, Ruby, dan Node.js) hingga yang memang spesifik dibuat untuk bahasa pemrograman tertentu seperti ASP, C++, Java, Lua/Corona SDK, Perl, PHP, Python dan Rubby. Untuk bahasa pemrograman PHP, yang umum digunakan adalah twitteroauth karya Abraham Williams yang merupakan pustaka PHP pertama yang mendukung OAuth Twitter REST API.

Proses pengambilan data melalui Twitter API juga memiliki aturan. Jumlah permintaan dibatasi pada jumlah tertentu dalam satuan waktu untuk menjaga server API Twitter tetap stabil. API Model v1.1 membatasi kemungkinan tingkat untuk rentang yang lebih luas melalui batas permintaan per-metode. Ada dua slot awal yang tersedia untuk permintaan GET: 15 panggilan setiap 15 menit, dan 180 panggilan setiap 15 menit [7].

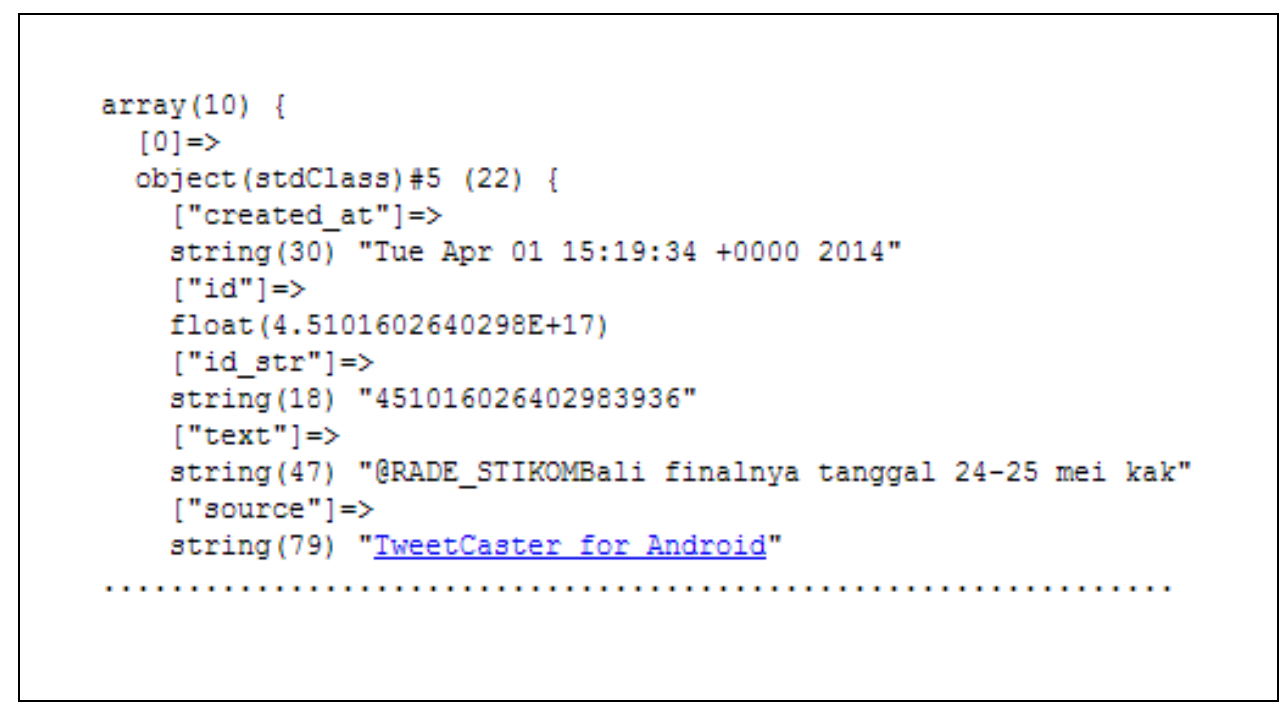

Gambar 5. Contoh format JSON yang di-return oleh Twitter API 


\section{HASIL DAN PEMBAHASAN}

Berdasarkan penjelasan pada bagian metode penelitian, sistem pengelola konten berbasis web memiliki banyak keunggulan dan solusi untuk memecahkan tantangan yang muncul untuk penerapan digital signagedengan pemroses inti mikrokomputer. Untuk mencapai tujuan tersebut, Drupal 7 digunakan sebagai sistem pengelola konten dan Raspi B yang bersistem operasi Raspbian Wheezy digunakan sebagai mikrokomputer pengolahnya. Contoh studi kasus yang digunakan pada penelitian ini adalah sebuah digital signageyang berfungsi untuk menampilkan informasi mengenai jadwal perkuliahan di Laboratorium Robotics and Embedded Systems STMIK STIKOM Bali. Digital signageini juga mampu menampilkan informasi pengumuman seputar kegiatan di Lab. Integrasi dengan media sosial Twitter dimanfaatkan untuk melakukan pemberitahuan cepat. Dosen atau staf pengajar yang berhalangan hadir cukup men-tweet informasi yang ingin disampaikan ke akun Twitter yang telah dihubungkan dengan API Twitter dengan format ber-hastag\#infodosen.

Sebuah script PHP yang berfungsi untuk mengambil data dari server API Twitter melakukan pengambilan data setiap tiga menit sekali. Hal ini bertujuan untuk menjaga agar ratelimit yang ditetapkan oleh Twitter tidak terlampaui. Script tersebut men-cache isi dari sepuluh Tweet terakhir yang di-mention oleh dosen atau staf pengajar ke file cache. Selanjutnya, block yang dipasang pada halaman web Drupal meminta update konten ke file cache tersebut secara diam-diam di latar belakang. Dengan men-cache isi dari pesan Twitter ke disk, bisa menghemat penggunaan bandwidth, dan menghindari block menampilkan pesan kosong apabila pada saat proses pengambilan/update data ke internet, terjadi masalah pada koneksi internet.

Untuk memenuhi fungsi tersebut, dibutuhkan bantuan dari fungsi sistem operasi. Fungsi scheduling dibutuhkan pada tahap ini, dan sistem operasi Debian memiliki fungsi scheduling yang umum digunakan pada distro Linux. Cron, time-based job scheduler pada sistem operasi unix-like. Dengan menggunakan cron bisa dibuat cronjob untuk melakukan update/pengambilan data setiap interval waktu tertentu. Contoh penggunaan cronjob untuk melakukan penjadwalan diperlihatkan pada Gambar 6.

Selain fungsi integrasi dengan media sosial Twitter, digital signageyang dibuat juga mampu melakukan pengambilan data ke situs luar. Peneliti mencoba menampilkan informasi cuaca di kota Denpasar yang didapat dari sumber informasi cuaca dunia non-profit openweathermap.org. Hasil mangenai informasi cuaca ini ditampilkan langsung pada Block Drupal dan di-update secara otomatis setiap 30 menit sekali. Selain informasi cuaca, informasi lainnya yang ditampilkan adalah news feed dari antaranews.com. Sumber berita terkini ditambahkan dan diperbaharui setiap 30 menit sekali. Tampilan akhir sistem informasi akademik pada Laboratorium Robotics and Embedded Systems STMIK STIKOM Bali ditunjukkan pada Gambar 7.

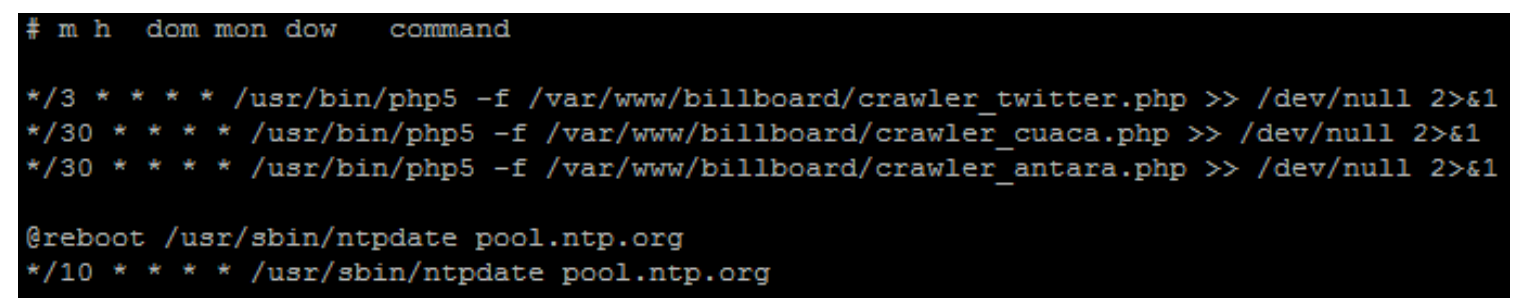

Gambar 6. Penggunaan cronjob untuk melakukan penjadwalan 


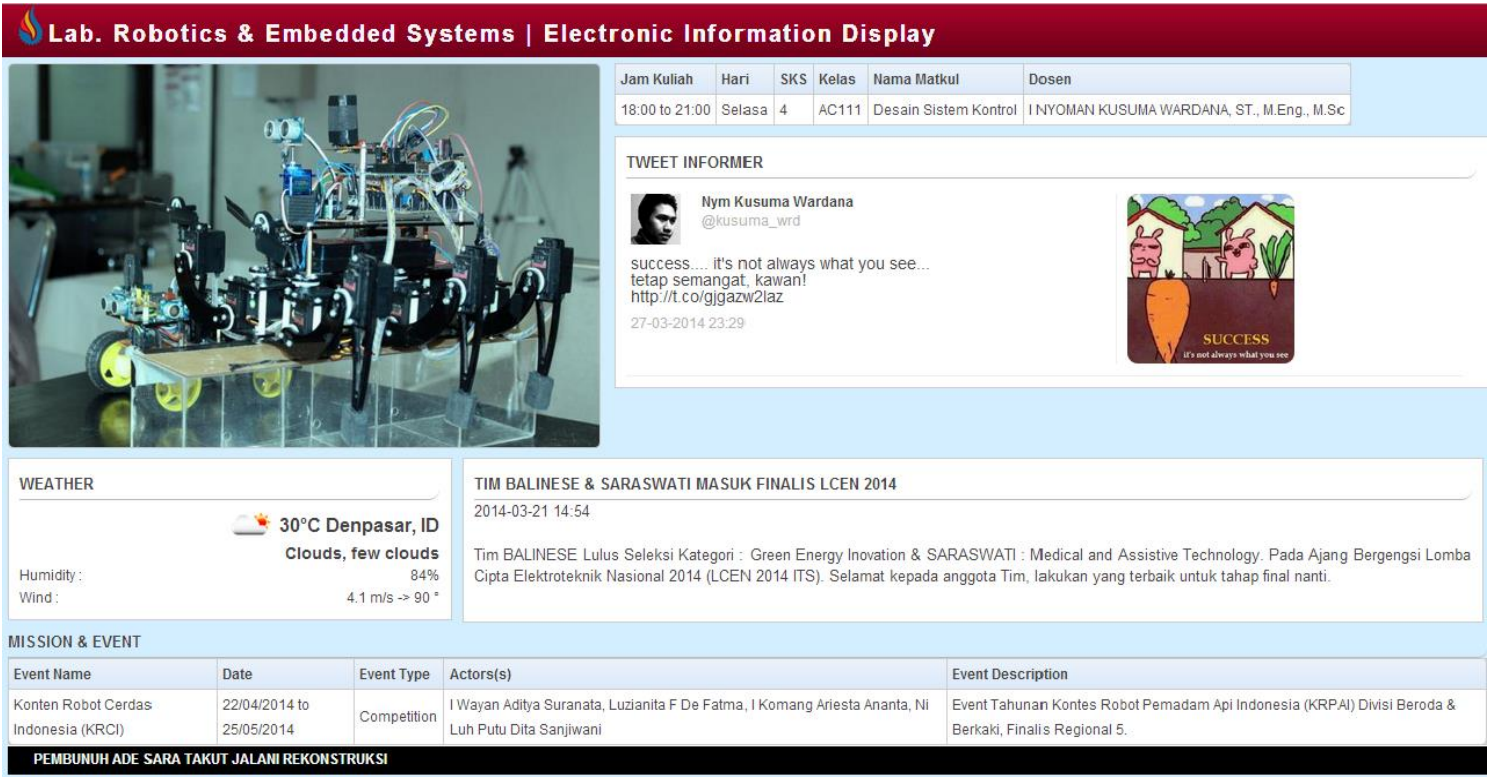

Gambar 7. Tampilan digital signage untuk kegiatan akademik

Berdasarkan analisis yang dilakukan peneliti selama melakukan percobaan, terdapat beberapa kelemahan yang dimiliki oleh mikrokomputer. Faktor keterbatasan fitur perangkat keras pada mikrokomputer tidak sebanding dengan fitur yang dimiliki oleh komputer desktop menyebabkan performa antarmuka administrasi pengelola konten menjadi kurang responsif. Namun demikian, performa ketika showtimemasih dapat berjalan dengan baik meskipun menggunakan antarmuka yang dinamis dan atraktif. Dengan perkembangan media digital signage yang semakin pesat, diharapkan alternatif penggunaan mikrokomputer sebagai mesin pemroses digital signage dapat diaplikasikan lebih luas.

\section{KESIMPULAN}

Penulis mencoba memanfaatkan mikrokomputer sebagai mesin pengolah digitalsignage yang menjalankan sistem pengelola konten berbasis web. Dari hasil uji coba yang dilakukan, sebuah mikrokomputer berarsitertur ARM (Raspiberry Pi Tipe B) berhasil menjalankan sistem pengelola konten berbasis web menggunakan Drupal. Konten yang dibuat berisikan konten richmultimedia, baik dari segi tampilan dan animasi serta kemampuannya untuk berinteraksi dengan situs luar seperti informasi cuaca, newsfeed, dan media sosial Twitter. Dengan perkembangan media digital signage yang semakin pesat, diharapkan alternatif penggunaan mikrokomputer sebagai mesin pemroses digital signage dapat diaplikasikan lebih luas. Berdasarkan analisis yang dilakukan peneliti selama melakukan percobaan, terdapat beberapa kelemahan yang dimiliki oleh mikrokomputer. Faktor keterbatasan fitur perangkat keras pada mikrokomputer tidak sebanding dengan fitur yang dimiliki oleh komputer desktop menyebabkan performa antarmuka administrasi pengelola konten menjadi kurang responsif.

\section{SARAN}

Beragam permasalahan mungkin akan dihadapi ketika melakukan oleh pengembang dan digital signageberbasis web dan mikrokomputer Raspi B. Dikarenakan mikrokomputer yang digunakan pada penelitian ini tidak dilengkapi dengan real time clock (RTC), maka disarankan untuk melakukan update waktu melalui internet setiap kali mikrokomputer dinyalakan atau setiap jangka waktu tertentu. Hal ini bisa dilakukan dengan memanfaatkan cronjob dan aplikasi 
updater waktu ntpdate. Hal ini akan mencegah terjadinya malfungsi yang berkaitan dengan filter yang berhubungan dengan waktu pada sistem pengelola konten dan sistem operasi, alternatif lain adalah dengan memasaing modul RTC tambahan melalui antarmuka GPIO yang dimiliki oleh mikrokomputer.

Selain itu, masalah dengan resolusi layar juga akan menjadi halangan. Tampilan signage kemungkinan akan menjadi kacau apabila ukuran layar monitor yang digunakan berganti-ganti. Hal ini dapat dihindari dengan membuat thema web dengan mode fluid dan mengatur resolusi layar pada file /boot/config.txt. Selanjutnya, thema Bootstrap dapat dijadikan sebagai solusi terhadap permasalahan layar ini.

Pengembangan lebih lanjut dimungkinkan untuk mengintegrasikan perangkat tambahan seperti sensor dengan mikrokomputer melalui interface GPIO yang dimiliki oleh Raspi B. Dengan interface ini berbagai perangkat yang mendukung komunikasi serial, SPI, dan I2C bisa dihubungkan dengan sistem pengelola konten untuk mendapatkan data dan melakukan interaksi dengan user.

\section{DAFTAR PUSTAKA}

[1] Kim, S., Park, E., Hong, S., Cho, Y., del Pobil, A. P., 2011, Designing Digital Signage for Better Wayfinding Performance: New Visitors' Navigating Campus of University, $4^{\text {th }}$ International Conference on Interaction Sciences: IT, Human and Digital Content, Busan, 16-18 Agustus 2011.

[2] Yin, K. C., Wang, H. C., Yang, D. L., Wu, J., 2012, A Study on the Effectiveness of Digital Signage Advertisement, International Symposium on Computer, International Symposium on Computer, Consumer and Control (IS3C), Taichung, 4-6 Juni 2012.

[3] Inoue, H., Suzuki, K., Sakata, K., Maeda, K., 2011, Development of a Digital Signage System for Automatic Collection and Distribution of Its Content from the Existing Digital Contents and Its Field Trials, International Symposium on Applications and the Internet (SAINT), Munich, Bavaria, 18-21 Juli 2011.

[4] Shirgaonkar, P., 2013, Drupal-Views \& SQL Analogy - An easier way to explain Views, http://www.acquia.com/blog/drupal-views-sql-analogy-easier-way-explain-views, diakses tanggal 03 April 2014

[5] Garrett, J. J., 2005. Ajax: A New Approach to Web Applications, http://www.adaptivepath.com/ideas/ajax-new-approach-web-applications.

[6] Ullman, C., Dykes, L., 2007. Beginning Ajax, Wiley Publishing, Canada.

[7] Tim twitter.com, REST API Rate Limiting in v1.1, https://dev.twitter.com/docs/ratelimiting/l.1, diakses tanggal 03 April 2014. 